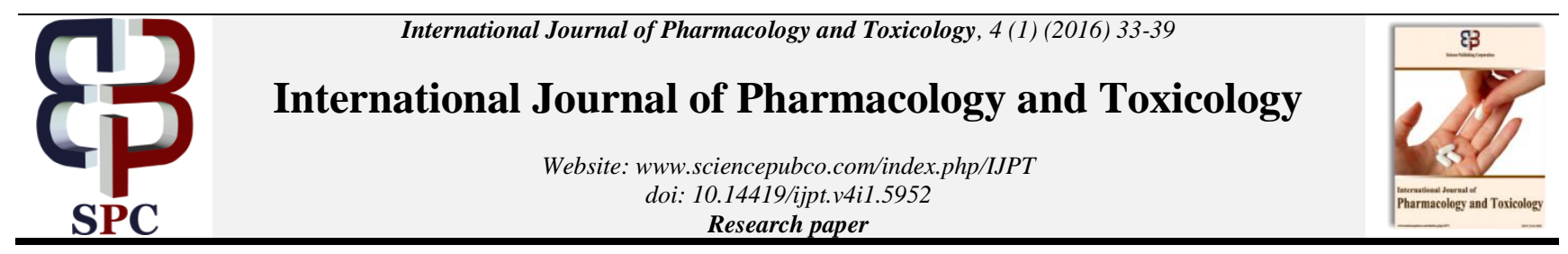

\title{
Epidemiology, presentation and integrated management of scorpion sting envenomation
}

\author{
Sandeep V. Binorkar ${ }^{1 *}$, Gajanan R. Parlikar ${ }^{2}$ \\ ${ }^{1}$ Assistant Professor, Dept. of Agadatantra, Govt. Ayurveda College, Nanded, Maharashtra, India \\ ${ }^{2}$ Ayurveda Extension Officer, Zilla Parihad, Sangli, Maharashtra, India \\ *Corresponding author E-mail:dr.sandeepb@gmail.com
}

\begin{abstract}
Scorpion sting is an overwhelming \& an endemic public health problem in some rural part of the India. Approximately 1,400 species of the Scorpion are found worldwide. 50 species out of 700, in India, can cause serious illness. Most of the studies have focused on the clinical and epidemiological aspects of scorpion stings. However, the venom of several scorpion species can trigger Cerebral, Cardiovascular $\&$ other systemic disturbances which may lead to death. Ayurveda has explained numerous medicinal preparations in the management of Vrishchika Damsha (Scorpion sting). This Paper highlights on the presentation of Scorpion sting and its acceptable prophylaxis and therapeutic protocols according to Ayurveda \& conventional medical science.
\end{abstract}

Keywords: Scorpion Sting; Integrative; Ayurveda; Mesobuthus; Anti Venom.

\section{Introduction}

Poison has been a challenge and threat to well-being; even existence of life. Ayurveda has mentioned the bite of Snakes, Insects, Spiders, Scorpion, and Rats etc. Jangama Visha, i.e. animate poisons, their characteristic symptoms and its management, in a very unique branch called as Agadatantra. (Kaviraj K.B. 2002) Among all these poisonous creatures insects occupy important cadre. In the present knowledge these insects are classified in various groups called Phylum, which are again subdivided in various groups known as classes. Phylum Arthropoda is the largest of the phyla in the animal kingdom and comprises six major classes one of an important group is class Arachnida. The major difference between an insect and an Arachnid is that the former has six legs and the later has eight legs. Arachnids are found throughout the world in nearly every habitat and are the most diverse group of animals. They include the scorpions, spiders, mites, ticks, and other eight-legged land invertebrates. (HH Sheikh et. al. 2005) Scorpions are venomous arthropods that belong to the class Arachnida. (Anonymous 2010).

In Ayurveda Vrishchika are considered as one of the Kita (insect) possessing the property to produce fatal signs and symptoms, and have been explained under the context of Jangama Visha by all the sages. (Jadavji T 2007).

\section{Epidemiology}

Scorpion stings are a major public health problem in many developing tropical countries, especially Sahelian Africa, South India, the Middle East, Mexico, and South Latin America. The estimated annual number of scorpion stings is 1.2 million leading to 32250 deaths. (Chippaux JP 2008) In India even though the epidemiological data is scarce, during $60 \mathrm{~s}$ and $70 \mathrm{~s}$, cases fatality rate of up to
$30 \%$ was reported from Kokan region of Maharashtra state alone. India stood among the topmost countries with a reported incident rate of $0.6 \%$. (Chippaux JP et. al. 2008) Cases of scorpion sting are reported more frequently during summer from March to June and hot months of September to October. In India endemic areas for such sting cases are western Maharashtra especially Konkan region, part of Karnataka, Andhra Pradesh, Sauraahtra a part of Gujarat state and Tamil Nadu. (Bawaskar H.S. et.al.2012).

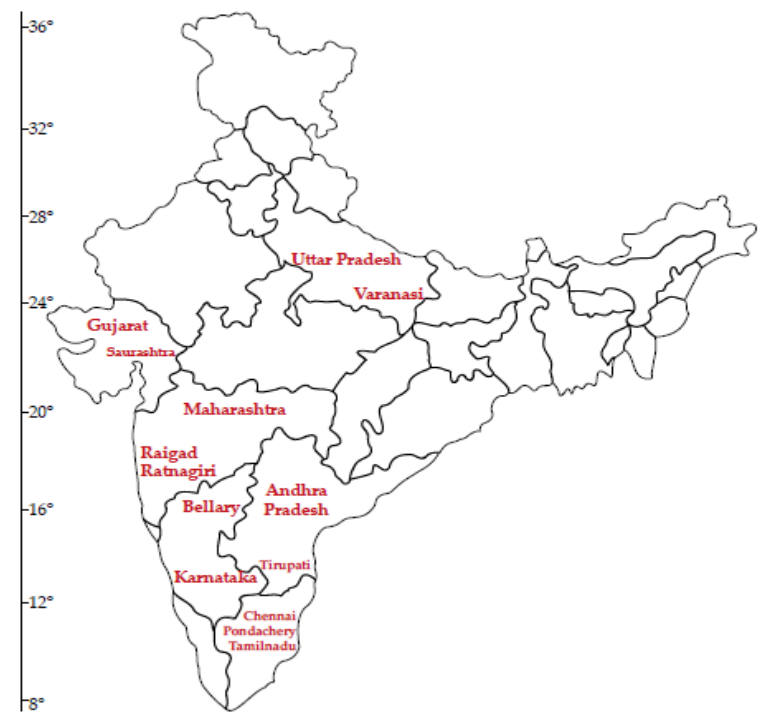

Fig. 1: Endemic Regions of Scorpion Sting in India. 


\section{Classification}

Scorpions are mainly classified in 7 families. There are approximately 1,500 species of scorpions known worldwide. (Available at http://emedicine.medscape.com/article/168230-overview (accessed on $21 \mathrm{Feb} 2016$ ) 50 species can cause serious illness. (Abhishek Srivastava et.al 2009) About $60 \%$ species are mild poisonous. Almost all of these lethal scorpions belong to the scorpion family called the Buthidae. The lethal members of the Buthidae family include the genera of Buthus, Parabuthus, Mesobuthus, Tityus, Leiurus, Androctonu \& Centruroides. Commonest species found in India are Buthus tamlus in houses, Palamaneus swammerdami, Buthus landersoni on coconut and palm trees, Lychas and Isometrus species. Available at http://www.azscorpion.com/india.html (access on 20 Feb 2016).

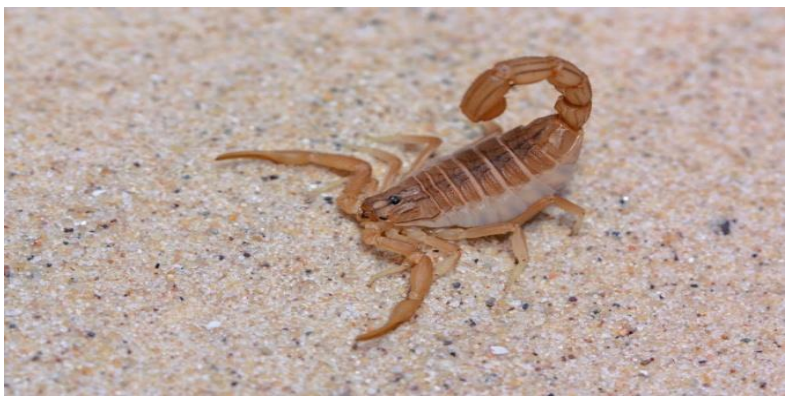

Fig. 2: Mesobuthus Tamlus.

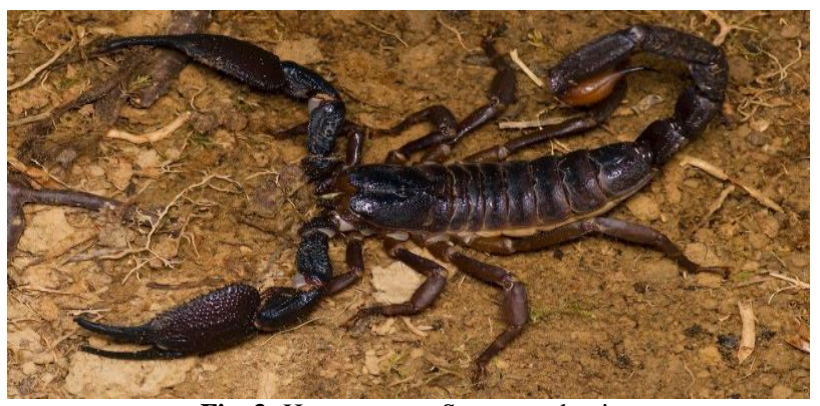

Fig. 3: Heterometrus Swammerdami.

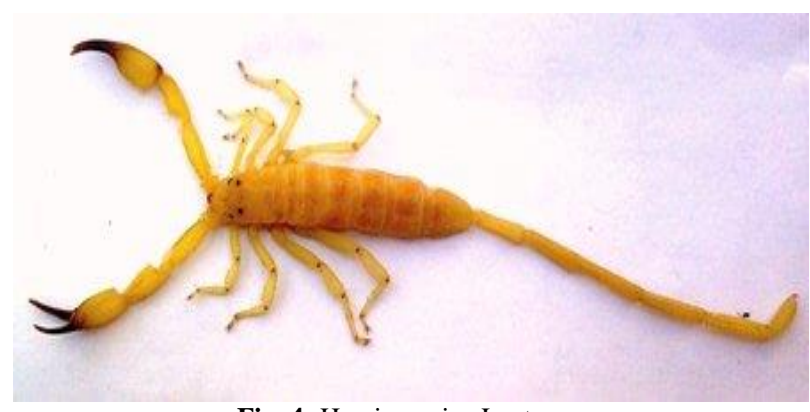

Fig. 4: Hemiscorpius Lepturus.

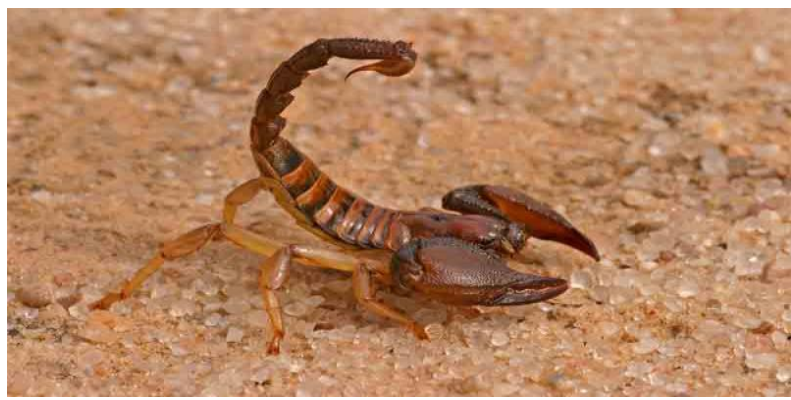

Fig. 5: Buthus Landersoni.

In Ayurveda Vrishchika, are being mentioned in Kita prakaranas, but it can produce more fatal symptoms as compared to other $\mathrm{Ki}$ tas. So it is no wonder that our Aachaaryas tried to classify these Vrishchika according to its potency to produce fatality.
Sushrutachrya has also divided Vrishchika according to their potency to create symptoms. He has classified them as (Su. K. 8/56)

(Kaviraj Kunjlal 1999)

1) Manda Visha (Mild)

2) Madhya Visha (Moderate)

3) Mahaa Visha (Virulent)

Table 1: Classification of Vrishchika

\begin{tabular}{llll}
\multicolumn{4}{c}{ Table 1: Classification of Vrishchika } \\
\hline Sl. & MandaVisha & MadhyaVisha & MahaaVisha \\
\hline 1 & Krishṇa & Rakta & Shwetaschitra \\
2 & Shyaava & Peeta & Shyaamala \\
3 & Karbura & Kapila & Dwiparva \\
4 & Gomootra & -- & Lohitaa \\
5 & Karkasha & -- & Rakta \\
6 & Mechaka & -- & Shweta \\
7 & Paaņdu varṇa & -- & Rakta neelodhar \\
8 & Peeta & -- & Peeta \\
9 & Dhoomra & -- & Neela \\
10 & Romasha & -- & Rakta Neela \\
11 & Satvala & -- & Neela shukla \\
12 & Rakta & -- & Ratobabhru \\
13 & -- & -- & Eka parva \\
14 & -- & -- & Parvani dvayi \\
15 & -- & -- & Aparva \\
\hline
\end{tabular}

\section{Pathophysiology}

Scorpion venom contains multiple neuro toxins and other compounds. (Dawn H. et.al. 2006) The venom is composed of varying concentrations of neurotoxin, cardiotoxin, nephrotoxin, hemolytic toxin, histamine, phosphodiesterases, phospholipases hyaluronidases, tryptophan, serotonin, glycosaminoglycans, and cytokine releasers \& enzyme inhibitors. (G. J. Müller 1993, M. C. E. Gwee et.al. 2002) Scorpions use last part of tail called as telson to inject the venom. The scorpion can voluntarily regulate how much venom to inject with each sting which is usually 0.1-0.6 mg. Scorpions with large venom sacs, such as the Parabuthus species, can even squirt their venom.

An experimental study after administration of intravenous Tc-99m labeled venom, the venom was found in the blood (28\%), muscles (30\%), bone (13\%) kidney (12\%) and liver (11\%) within 5 minutes. (Murugesan S. et.al. 1999) It shows the tremendous velocity of the venom to spread in the body, supporting the concept of Vyavayi guna of Visha explained in Ayurvedic texts. The potency of the venom varies with the species, with some producing only a mild flu and others producing death within an hour. The signs of the scorpion envenomation are determined by the following: (a) scorpion species, (b) venom composition, and (c) the victim's physiological reaction to the venom. (Vera L. 2010) The symptoms of the sting start immediately with a few minutes after the sting and usually progress to a maximum severity within 5 hours. (D. Mebs 2002) generally the venom is distributed rapidly into the tissue if it is deposited into a venous structure. Venom deposited via the intravenous route can cause symptoms only 4-7 minutes after the injection. The more rapidly the venom enters the bloodstream, the higher the venom concentration in the blood and the more rapid the onset of systemic symptoms.

Scorpion venom is a water-soluble, antigenic, heterogenous mixture, as demonstrated on electrophoresis studies. (Shyam Mathur et.al. 2010) This heterogeneity accounts for the variable patient reactions to the scorpion sting. The various constituents of the venom may act directly or indirectly and individually or synergistically to manifest their effects. In addition, differences in the amino acid sequence of each toxin account for their differences in the function and immunology. Thus, any modifications of the amino acid sequence result in modification of the function and immunology of the toxin.

The most important clinical effects of envenomation are neuromuscular, neuro autonomic, or local tissue effects. Autonomic excitation leads to cardiopulmonary effects observed after some scorpion envenomations. Somatic and cranial nerve hyperactivity results from neuromuscular over stimulation. Additionally, sero- 
tonin may be found in scorpion venom and is thought to contribute to the pain associated with scorpion envenomation.

The most potent toxin is the neurotoxin, of which 2 classes exist Both of these classes are heat-stable, have low molecular weight, and are responsible for causing cell impairment in nerves, muscles, and the heart by altering ion channel permeability. (Chippaux JP et. al. 2008) It also suggests that fatality of these scorpions is also related to the type of its origin which can be considered as its natural habitat.

According to Ayurveda these Scorpions are born from the putrefied dung of the cow, wood and bricks, cadaver of the animals killed by the poisoned arrow and the cadaver of the snakes. Total Number of scorpions is mentioned as 30 in the classics (Kaviraj K.B. 2002) though certain traditional books like Kriya Kaumudi explains 67 types of Scorpions depending on the predominance of Dosha. (V. M. Kuttikrishna Menon 1986)

The poison of the Vrishchika i.e. Scorpion is penetrating. In the beginning it causes burning sensation just like that of the fire After that it spreads upwards quickly and then gets stabilized at the site of the sting. Due to this there is severe pain, blue colour, pricking and bursting pain at the site. Person may develop swelling of the tongue, rigidity of the body, fever, and black coloured blood oozing out from all the orifices. There may be a loss of sensory perception also. Symptoms are also mentioned depending on the predominance of Dosha. In Prayoga Samuchchaya and Kriya Kaumudi signs and the symptoms of Vrishchika Damsha are expressed hierarchies as it enters deeper and deeper in subsequent Dhaatus. It is called as Vegas of Vrishchika Damsha.

\begin{tabular}{lll} 
& Table 2: Dhaatugata Lakshana of Vrishchika Visha \\
\hline Dhaatu & Pra. Sam. & Kri. Kau. \\
\hline Twak & Severe Pain & Pricking-pain, Vomiting, \\
Rakta & Severe Burning & Delirium, Convulsions \\
Mamsa & Hidhma, Oedema & Granthi + Burning, Jwara, Atisaara \\
Meda & Greevabhanga & Hidma, Gala shosha \\
Asthi & Jwara & Jwara. \\
Majja & Manastaapa, Dukha & Vyasana, Manastaapa \\
Shukra & Rakta Netra, Death & Rakta netrata, Death \\
\hline
\end{tabular}

In Present days several cases of scorpion stings are reported regularly with miscellany of symptoms.

\subsection{Local signs}

\subsubsection{Neurotoxic local effects}

Local pain progresses to generalized symptoms which may last up to 30 hours. A sharp burning pain sensation at the sting site, followed by pruritus, erythema, local tissue swelling, ascending hyperesthesia, may be reported. (Bawaskar HS et.al. 1998) This may persists for several weeks, and is the last symptom to resolve before the victim recovers. Sometimes Local evidence of a sting may be minimal or absent in as many as $50 \%$ of cases of neurotoxic scorpion stings. (Vera L. 2010).

\subsubsection{Cytotoxic local effects}

A macule or papule appears initially at the sting site, within the first hour of the sting. (Bawaskar HS et.al. 2012) The diameter of the lesion is dependent on the quantity of venom injected. The lesion progresses to a purpuric plaque that will ulcerate and necrose. Swelling is also seen in most of the cases. Lymphangitis results from the transfer of the venom through the lymphatic vessels. Pain, erythema, indurations, and wheal may be present. (Bawaskar HS et.al. 2012, Available at http://scorpionforum.darkbb.com/t772-scorpion-stinginformation-part-i-v (assessed on 15 Jan 2016).

\subsection{Systemic signs}

\subsubsection{Neurological signs: systemic symptoms are produced by} both sympathetic and parasympathetic stimulation

(Romero N. O. 2005) Most of the symptoms are due to either the release of catecholamine from the adrenal glands (sympathetic nerves) or the release of acetylcholine from postganglionic parasympathetic neurons. Adrenergic signs occur at a low venom dose, while cholinergic signs occur at high venom dose. However, dual manifestations of the adrenergic and cholinergic signs are possible because of varying organ system sensitivities to these neurotransmitters. (Bawaskar HS et.al. 2012)

\subsubsection{Central nervous system signs: patients may experience venom-induced cerebral thrombosis strokes}

Thalamus-induced systemic paresthesia may occur in all limbs. Cerebral oedema may also be seen in pediatric cases associated with scorpion stings. (Romero N. O. 2005) The level of consciousness of the patient may be altered, especially with restlessness, confusion, or delirium. Patients may have abnormal behavior. Ataxia is also a sign.

4.3. Autonomic nervous system signs: predominantly sympathetic signs, parasympathetic signs, or combination of both can be seen.

\subsubsection{Sympathetic signs}

Tachycardia, hypertension, Hyperkinetic Pulmonary edema, and seizures, can describe sympathetic involvement. This may be associated with hyperthermia, tachypnea, arrhythmia hyperglycemia, piloerection, restlessness, hyper excitability and convulsions.

\subsubsection{Parasympathetic signs}

Parasympathetic symptoms include the "SLUDGE" syndrome (salivation, lacrimation, urination, defecation, gastric emptying), bradycardia, and hypotension. (Bawaskar HS et.al. 2012, Janice Z 2003, Available at http://good.all-up.com/t1-scorpion-stingscorpion-envenomation (assessed on 1 Feb 2016) Parasympathetic signs like Broncho constriction, Rhinorrhea and bronchorrhea, Goose pimple skin, Loss of bowel and bladder control, Priapism, Dysphagia, Miosis, Generalized weakness can also be seen in the patients suffering from Scorpion sting. Patients may complain of trouble swallowing.

\subsubsection{Somatic signs}

Rigid spastic muscle of the limbs, involuntary muscle spasm, twitching, clonus, and contractures are the common ones.

\subsubsection{Cranial nerve signs}

Ptosis, Nystagmus, and blurred vision are common. Some times Mydriasis is also seen. Patients may have tongue fasciculations. Dysphagia, dysarthria, and stridor occurs secondary to pharyngeal reflex loss or muscle spasm. Available at http://good.allup.com/t1-scorpion-sting-scorpion-envenomation (assessed on 1 Feb 2016)

Peripheral nervous system signs -Intense local burning pain with swelling at the site of sting followed by ascending numbness and tingling, followed by paralysis and convulsions can be expected. (Bawaskar HS 2012)

\subsection{Non-neurologic systemic signs}

\subsubsection{Cardiovascular signs}

The toxin acts by opening sodium channel at presynaptic nerve terminals and inhibiting calcium dependant potassium channels. 
Autonomic storm is thus initiated. ((S. Mahadevan 2000) Cardio vascular signs in a patient suffering from Scorpion sting usually follow a pattern of a hyperdynamic phase followed by a hypodynamic phase. Hypertension may be secondary to catecholamine and renin stimulation. It may lasts for few hours \& may be high enough to produce hypertensive encephalopathy. (Bawaskar HS 2012, 1998) Raised angiotensin I levels have also been documented which further facilitate the sympathetic outflow through conversion to angiotensin II. (Gueron M et.al. 1980) Hypotension is less common and occurs secondary to excess acetylcholamine or catecholamine depletion. Tachycardia is greater than 130 beats per minute, although in some cases bradycardia can be observed. Cardiovascular collapse occur secondary to biventricular dysfunction and profuse loss of fluids from sweating, vomiting, diarrhea, and hyper salivation. (S. Mahadevan 2000)

\subsubsection{Respiratory signs}

Tachypnea may be present. Pulmonary edema with hemoptysis may be observed in some cases. It may be secondary to a direct toxin-induced increased pulmonary vessel permeability effect and may also be secondary to catecholamine-induced effects of hypoxia and intracellular calcium accumulation, leading to a decrease in left ventricular compliance with resultant ventricular dilation and diastolic dysfunction. Respiratory failure is generally secondary to paralysis of diaphragm alveolar hypoventilation, and bronchorrhea. (Bawaskar HS 2012, Patel B.G. et.al. 1989)

\subsubsection{Gastrointestinal signs}

Excessive salivation is one of the common sign seen associated with nausea and vomiting. Dysphagia is also possible. Gastric hyper distention occur secondary to vagal stimulation. Acute pancreatitis may lead to hyperglycemia. (Bawaskar H.S. 1999)

\subsubsection{Allergic signs}

Patient with the Scorpion sting may show following allergic signs. Patients may have urticaria. Angioedema can also be seen in few cases. Patients may present with bronchospasm. Anaphylaxis is also possible.

\subsubsection{Genitourinary signs}

Decreased renal plasma flow, Toxin-induced acute tubular necrosis and renal failure may be seen. Rhabdomyolysis, renal failure may result from venom-induced excessive motor activity. Sometimes Priapism occur secondary to cholinergic stimulation. (Bawaskar HS 2012, Patel B.G. et.al. 1989)

\subsubsection{Hematological signs}

Platelet aggregation may occur because of catecholamine stimulation. Disseminated intra-vascular coagulation with massive hemorrhage may result from venom-induced defibrination. (Murthy KRK et.al.1988, Suman sarkar 2008)

\subsubsection{Metabolic signs}

Hyperglycemia may occur from catecholamine induced hepatic glycol genolysis, pancreatitis, and insulin inhibition. (Murthy RK et.al. 2002) Increased lactic acidosis may occur from hypoxia and venom-induced increased lactase dehydrogenase activity. Patients may have an electrolyte imbalance and dehydration from hyper salivation, vomiting, diaphoresis, and diarrhea. Toxin-induced uterine contractions may also seen resembling to the pregnancy sign in women. This may lead to abortions in pregnant women. (Patel B.G. et.al. 1989)

\section{Lab studies \& investigations: (bawaskar HS 2012)}

\subsection{Count for leukocytosis and hemolysis}

5.1. Electrolyte evaluation in patients with venominduced salivation, vomiting, and diarrhoea

5.2. Coagulation parameters should be measured for venom-induced defibrination because, at high concentrations, the venom is an anticoagulant

5.3. Glucose levels should be measured to evaluate for hyperglycemia from liver and pancreas dysfunction and suppression of insulin secretion

5.4. Creatine kinase and urinalysis help evaluate for venom-induced excessive motor rhabdomyolysis

5.5. Obtain amylase/lipase values to assess for pancreatitis

5.6. Patients may have increased aspartate aminotransferase and alanine aminotransferase levels from venominduced liver cell destruction

5.7. Increased catecholamine, aldosterone, renin angiotensin, and antidiuretic hormone levels are detected a few hours after the sting. The increased levels persist for 6 hours, after which a gradual decline occurs

5.8. Interleukin (IL)-1 level are elevated in all envenomations

5.9. High levels of IL-6, interferon-gamma, and granulocyte-macrophage colony-stimulating factor are present in severe envenomations

5.10. Radio labeled antibodies or immuno-enzymatic assays help quantify the serum venom level because an association exists between the clinical signs of envenomations and this level

\section{Imaging studies}

6.1. Unilateral pulmonary edema may be seen on chest $x$-ray films because of the venom effect on pulmonary vascular permeability.

6.2. Echocardiography is more sensitive than Electrocardiography and creatine kinase assays for assessing myocardial compromise after a scorpion sting. It can rule out global biventricular hypokinesis with a decreased left and right ventricular ejection fraction. This dysfunction can appear just a few hours after the sting and usually normalizes within 4-8 days.

6.3. Serial echocardiography findings show that the return of left ventricular function to a normal state correlates to clinical cardio respiratory improvement. 


\subsection{Electrocardiogram}

\subsubsection{ECG changes persist for 10-12 days before normalizing}

6.4.2. Rhythm disturbances are not dose-dependent but are related to the venom composition

\subsubsection{Sinus tachycardia - Most common rhythm}

\subsubsection{QTC prolongation}

\subsubsection{ST changes}

\subsubsection{T-wave inversion}

\subsubsection{Ventricular repolarization abnormalities}

\subsubsection{Bundle-branch block}

\subsubsection{First-degree block}

6.4.10. A possible sequence of ECG changes has been noted. this sequence starts with bizarre, broad-notched, biphasic, peaked $t$ waves with a beat-to-beat variation. this bizarre $t$ wave is followed by the appearance of tiny $q$ waves and then atrio-ventricular dissociation with an accelerated junction rhythm

6.5. Color-flow Doppler study findings show mitral incompetence, probably secondary to venom-induced dilated cardiomyopathy.

\section{Other tests}

7.1. Arterial blood gas determinations show a decrease in arterial oxygenation tension and an increase in PCO2 within 15 minutes of the envenomation, with mild metabolic acidosis

7.2. Pulmonary artery catheterization findings may include the following

7.3. Elevated systemic vascular resistance occurs up to 4 times the normal level, with elevated mean arterial pressure (MAP) of $203 \mathrm{~mm} \mathrm{Hg}$

\subsection{Left ventricular failure produces a MAP of 57-69 mm Hg}

\subsection{Biventricular failure reduces a MAP of $47 \mathrm{~mm} \mathrm{Hg}$}

7.6. Serial spirometry measurements may help to detect impending venom-induced diaphragmatic failure

\section{Management of scorpion sting in Ayurveda}

8.1. According to Ayurveda management of vrishchika damsha can be divided in to two parts as

8.1.1. Yukti vyapaashraya chikitsa: it includes use of various medicinal preparations for external as well as internal purpose. yukti vyapaashraya chikitsa can again be divided in two major parts as follows

8.1.2. Shodhana chikitsa - in bahula dosha condition - this may include vamana (emesis), virechana (catharsis), nasya (nasal medication) \& raktamokshana (blood letting) according to the predominance of the dosha

8.1.3. Shamana chikitsa - in alpa dosha - includes internal and external application medicine along with certain procedures like dhoopana, anjana etc

8.1.4. Daiva vyapaashraya chikitsa: it includes mantra prayoga. (g sukla 2006)

Following are certain Shamana drugs useful in scorpion sting In the poison, which is predominant in Vaata, the wound should be smeared with Pinyaka (oil cake of Tila) anointing with medicated oil, fomentation by the steam coming out from a tube or by application of boiled rice etc. and therapies which are Brimhana (nourishing) should be used. (Shivprasad Sharma 2006)

Agada made up of Vacha (Acorus calamus Linn.), Hingu(Ferula narthex Boiss), Vidanga (Embelia ribes Burm), Saindhava (Rock salt), Gajapippalee (Piper chaba Hunter), Patha (Cyclea peltata), Prativisha (Aconitum heterophylum Wall) and Vyosha i.e. Shunthi (Zingiber officinale Rosc), Maricha (Piper nigrum Linn) and Pippali (Piper longum Linn) is called as Dashanga Agada which is indicated to treat the poisons of all kinds of insects. This Agada is found to be significantly effective in clinical trials of scorpion sting cases. (Shivprasad Sharma 2006, Binorkar S.V. et al 2013) Other herbo-mineral compound preparation consisting Bilva (Aegle marmelos Corr), Surasa (Ocimum sanctum Linn.), Karanja (Pongamia pinnata Perri.), Tagara (Valeriana wallichii DC), Devadaru (Cedrus deodara Roxb.), Haritaki (Terminalia chebula Retz.), Vibhitaki (Terminalia bellirica Roxb.), Amalaki - (Emblica officinalis Gaertn), Shunthi (Zingiber officinale Rosc.), Maricha (Piper nigrum Linn.), Pippali (Piper longum Linn.), Haridra (Curcuma longa Linn.), Daruharidra (Berberis aristata DC.), triturated with Aja mutra (Goat's Urine) known as Bilwadi Agada is also reported significantly effective in treating cases of scorpion sting. (Shivprasad Sharma 2006, Binorkar S.V. et al 2013)

Rakta mokshana (blood letting) at the site if sting with the help of Shringa (horn) or Jalauka (Leech). Nasya with swarasa of Ashwagandha (Withania somnifera) and Karanja (Pongamia pinnata Perri.) Anjan (Corylym) with Karanja (Pongamia pinnata Perri.), Tintidika (Rhus parviflora), Karaskara patra (Strychnos nuxvomica) and Saindhava (rock salt). Dhaara with Nimbatwak and Maricha (Piper nigrum Linn) grinded in butter milk which is sour in taste may be administered. (Shivprasad Sharma 2006) Dhaara should be done when it is Luke warm. Karanjapatra swarasa, which is obtained by crushing the leaves in hand, is also a useful remedy. It can be administered as a Pana (drinking), Anjana, Nasya and Lepa. External application of Ghrita (Clarified butter) and Saindhava (Rock salt) in the form of Dhara when poured in luke warm form at the site of scorpion sting is also effective alone to reduce the radiating pain in sting cases significantly. (Shivprasad Sharma 2006, Binorkar S.V. et al 2013) Apart from these, there are several single herbs used in the management of scorpion sting in traditional practices. (Binorkar Sandeep V. 2012) The efficacy of most of these herbs has been endorsed by scientific researches.

\section{Modern management}

After a sting by a dangerous species, it is important for patients to stay calm in order to minimize absorption of venom into the body. A pressure dressing over the sting site may be helpful, as well as application of ice packs. In adults, symptoms may be self-limited with resolution occurring in several hours. Administration of a potent antivenin within a couple of hours of the sting may be needed for treatment of severe envenomation. Antivenins are commercially available for many (but not all) of the dangerous scorpions. There is some controversy concerning antivenin use; the best course may be to evaluate and administer antivenin only as needed. But there may be serum sickness in the patients after the administration of Scorpion antivenin. Scorpion sting therapy 
may include mechanical ventilation to improve oxygenation \& administration of CNS depressants such as midazolam (a benzodiazepine) and vasodilators such as selective $\alpha 1$ blockers and calcium channel blockers. (Boyer LV et.al. 2009) Others have used intravenous propranolol HCL. (Bawaskar H.S. 1999)

\subsection{Anti-scorpion venoms}

Species-specific anti-venom is used for certain deadly scorpions. Despite to theoretical advantages of scorpion anti-venom, its use is very controversial. Scorpion anti-venom in India and in other parts of the world is prepared from animals, such as horses or goats, which have been exposed to low levels of toxin extracts from regional species. Since anti-venom contains foreign antigens the risk of serum sickness is always present. Moreover it is not free from anaphylaxis. But over-all mortality rate was reduced from 4 $-6 \%$.

Table 3: Scorpion Antivenin

\begin{tabular}{lll} 
& \multicolumn{2}{c}{ Table 3: Scorpion Antivenin } \\
\hline Sr. & Place & Anti-Scorpion venom. \\
\hline 1 & INDIA & Anti-Mesobuthus \\
2 & USA and Mexico & Anti-Centruroides \\
3 & America & Anti-Tityus \\
4 & South Africa & Anti-Parabuthus \\
5 & Egypt and Israel & Anti-Leiurus \\
\hline
\end{tabular}

\subsection{Other associated treatment}

9.2.1. Reassurance- most important to avoid psychological affects of the sting

9.2.2. Infiltration of local anesthetic agent i.e. 2\% Xylocaine (i.e. lidocaine) without adrenaline, gives temporary relief from pain

9.2.3. Intravenous administration of $10 \mathrm{ml}$ of a $10 \%$ solution of calcium gluconate over 10-20 minutes can decrease muscle pain and cramps for a short time

9.2.4. Local pain and paresthesia both at the site and periphery are best treated with local compress and oral analgesia

9.2.5. Oral Non-steroidal anti-inflammatory drugs (NSAID) with antacids are also helpful to reduce the pain and Swelling.

9.2.6. Dehyroemetine hydrochloride injected at the sting site gives prolonged relief

\subsubsection{Anxiolytic like Diazepam may also be used}

9.2.8. Propped up position, oxygen, intravenous aminophylline, repeat dose of prazosin are helpful in the management of pulmonary oedema. Stimulation of Alpha receptors plays an important role in the pathogenesis of scorpion sting. (Gwee MCE et.al. 2002, Frire-_maia L et.al. 1974 Gupta V. 2006)

9.2.9. Sublingual iso-sorbide dinitrate or NTG and then sodium nitroprusside drip may also indicated in this condition but such situation is rarely arises if prazosin administered earlier

9.2.10. For the reduction in the insulin level (Poonking $\mathrm{T}$ 1963, Mahadevan $S$ et. al., 1981) insulin-glucose therapy is also advised. 0.3 units of regular insulin/g of glucose and glucose at the rate of 0.1 $\mathrm{g} / \mathrm{kg} / \mathrm{hr}$. This glucose insulin is to be given as continuous infusion

9.2.11. Dopamine or dobutamine drip in $5 \%$ glucose $(5-7$ $\mathrm{mcg} / \mathrm{kg} / \mathrm{minute}$ ) may also be simultaneously given to maintain the blood pressure

9.2.12. If the patient presents with the hypertension during the initial phase of transient hypertension, give sublingual nifedipine $5 \mathrm{mg}$ in children and $10 \mathrm{mg}$ in adults

9.2.13. Immunization for tetanus

\section{Prognosis}

Death is probably due to respiratory paralysis, peripheral vascular failure, and/or myocarditis, and it may occur at any interval between 1.5 to 42 hours. Children are at greatest risk of severe reactions. Furthermore, surviving the first 24 hours after a scorpion sting also carries a good prognosis. It has been also mentioned that the prognosis is better in the victims with more pain. (Bawaskar H.S. 1999) Literatures from Ayurveda state that the prognosis is poor if sting is by the Sannipataja or Tikshna Visha Vrishchika. (Shivprasad Sharma 2006)

\section{Conclusion}

The context of Vrishchika has been mentioned in several classical texts of Ayurveda with numeral formulations for its alleviation. These formulations should be evaluated with present parameters. As the venom stays in the body for more than 36 hours, nutrilizing the venom should be the first and only line of treatment. Scorpion stings cause a wide range of conditions, from severe local skin reactions to neurologic, respiratory \& cardiovascular collapse. Envenomation from most scorpions results in a simple, painful, local reaction that can be treated with analgesics, antihistamines \& symptomatic care. Beside this in conventional medical science as well several medicines are utilized along with Scorpion antivenom, but the result always depend on the initiation of the therapies at precise moment. There are few limitations for the use of these medicines which may alter the final outcome and hence should be defined with rigorous clinical trials.

\section{References}

[1] Abhishek Srivastava et.al., (2009) Scorpion Sting Envenomation With Pulmonary Odema \& Hypotension: Treated With NTG \& Inotropic Support: A Case Report - The Indian Anaesthetists’ Forum, Jodhpur

[2] Anonymous, (2010) Guide to Insect and Non-Insect Arthropods Entomology Study Materials - Agri Life Extention - Texas A\&M University

[3] Bawaskar H.S. (1999) Scorpion sting - Clinical Manifestation, Management \& Literature, 1st Edition, Published by- Popular Prakashan Pvt. Ltd, Mumbai.

[4] Bawaskar Himmatrao Saluba *, Pramodini Himmatrao Bawaskar, (2012) Scorpion Sting :Update, JAPI, Vol. 60:46-55

[5] Bawaskar HS, Bawaskar PH. (1998) Indian red scorpion envenoming- Indian J Pediatr; 65: pp 383-391. http://dx.doi.org/10.1007/BF02761131.

[6] Binorkar S V, CM Sreekrishnan, Asha KV. (2013) Role of Bilwadi agada in the management of Scorpion sting. Int. J. Res. Ayur. Pharm, 4(1):59-62

[7] Binorkar S.V. et al (2013) Evaluation of 'Dashanga Agada' (HerboMineral Compound) in the Management of Scorpion Sting Envenomation, Asian Journal of Pharmaceutical Research and Development, 1(4):126-133

[8] Binorkar Sandeep V., (2012) Herbal Medicines Used in the Management of Scorpion Sting in Traditional Practices - A Review, Am. J. PharmTech Res. 2(3):243-256

[9] Boyer LV et.al, (2008) Antivenom for critically ill children with neurotoxicity from scorpion stings, The New England J Med 2009; 360:2090-2098, http://dx.doi.org/10.1056/NEJMoa0808455.

[10] Chippaux JP, Goyffon M. (2008) Epidemiology of scorpionism: a global apprasial. Acta Trop. 107(2):71-9. http://dx.doi.org/10.1016/j.actatropica.2008.05.021.

[11] Mebs, (2002) "Scorpions and snakes, such as cobras, mambas and vipers made the African continent famous for venomous animals," Bulletin de la Societe de Pathologie Exotique, vol. 95, no. 3, pp. 131

[12] Dawn H. Gouge and Carl Olson (2006), Scorpions - The University of Arizona, College of Agriculture \& Life Sciences, pp 1-6

[13] Frire- maia L, Pinto GI and Franco I. (1974) Mechanism of cardiovascular effects produced by purified scorpion toxin in the rat. $\mathrm{J}$ Pharm Theap 188:207-13. 
[14] G. J. Müller, (1993) "Scorpionism in South Africa. A report of 42 serious scorpion envenomations," South African Medical Journal, vol. 83 , no. 6 , pp. $405-411$,

[15] Girijadayalu Sukla (2006) - Bhel Samhita, Chaukhamba Bharati Academy, Varanasi

[16] Gueron M, Adolph RJ, Grupp IL. (1980) Hemo-dynamic and myocardial consequences of scorpion venom. Am J Cardiol 45: pp 979 $986 \mathrm{http}: / / \mathrm{dx}$. doi.org/10.1016/0002-9149(80)90166-6.

[17] Gupta V. (2006) Prazosin: pharmacological antidote for scorpion $\begin{array}{lllll}\text { envenomation. } & \mathrm{J} & \text { Trop } & \text { Peditr } & \text { 52:150-1 }\end{array}$ http://dx.doi.org/10.1093/tropej/fmi097.

[18] Gwee MCE, Nirtthanan S, Khoo H, Gopalkrishnakone P, Kini MR Cheah LS. (2002) Autonomic effects of same scorpion venoms and toxins. Clinical experimental pharmacology and Physiology 29:795-801. http://dx.doi.org/10.1046/j.1440-1681.2002.03726.x.

[19] HH Sheikh Hamdan bin Zayed Al Nahyan, Michael Gillett and Conrad Gillet \& others (2005)- The Emirates A Natural History Peter Vine Publisher - Trident Press Limited - Abu Dhabi -pp174

[20] http://emedicine.medscape.com/article/168230-overview (access on 21 Feb 2016)

[21] http://good.all-up.com/t1-scorpion-sting-scorpion-envenomation (assessed on 1 Feb 2016)

[22] http://scorpionforum.darkbb.com/t772-scorpion-sting-informationpart-i-v (assessed on 15 Jan 2016)

[23] http://www.azscorpion.com/india.html (access on 20 Feb 2016)

[24] Jadavji Trikamji Acharya, (2007) Charaka Samhita, Chakrapani tika, Chikitsa sthana, Chapter 23, Reprint, Chaukhambha Prakashan, 571-582

[25] Janice Zimmerman -(2003) Poisonings and Overdoses - ACCP Critical Care Board Review: pp 365-376

[26] Kaviraj Kunjlal Bhishagratna, (1999) Sushruta Samhita, Kalpasthana, Chapter VIII, Vol III, C1st Edn, Choukhambha Sanskri Series, Varanasi, 96-97

[27] Kaviraj Kunjlal Bhishagratna, (2002) Sushruta Samhita, Sutrasthana, Chapter 1, Vol I, 2nd Edn, Choukhambha Sanskrit Series, Varanasi, 4-5

[28] M. C. E. Gwee, S. Nirthanan, H.-E. Khoo, P. Gopalakrishnakone, R. M. Kini, and L.-S. Cheah, (2002) "Autonomic effects of some scorpion venoms and toxins," Clinical and Experimental Pharmacology and Physiology, , vol. 29, no. 9, pp. 795-801 http://dx.doi.org/10.1046/j.1440-1681.2002.03726.x.

[29] Mahadevan S, Chudhury P, Puri PK and Srinivasan S. (1981) Scorpion envenomation and role of the lytic cocktail in its management. Ind J Peditr; 48:757-61. http://dx.doi.org/10.1007/BF02758544.

[30] Murthy KRK, Zolfagharian H, Medh JD, Kudalkar JA, Yeolekar ME, Pandit SP, et al. (1988) Disseminated intravascular coagulation and disturbances in carbohydrate and fat metabolism in acute myocarditis produced by scorpion (Buthus tamulus) venom. Indian J Med Res 87:pp 318-325.

[31] Murthy Radha Krishna K., M. Abbas zare - (2002)Scorpion Antivenom Reverses Metabolic, Electrocardiographic, And Hormonal disturbances caused by the Indian red scorpion Mesobuthus tamulus concanesis, pocock envenomation Journal of Venomous Animals and Toxins, Vol.8 no. 1

[32] Murugesan S, Radhakrishnamurthy k, Noronha OPD, Samuel AM (1999) Tc-99m scorpion venom: labeling, biodistribution and scinti imaging. J Venom Anim Toxins; 5:35- pp 46.

[33] Patel B.G., M. Bhatt \& K.C. Dave - (1989) Effects of Scorpion Venom (Buthus Tamulus) on Blood Pressure, Respiration \& Electrocardiographic recordings in Anaesthetized Albino Rats, Indian Journal of Pharmacology 21: pp 38-45.

[34] Poonking T. (1963) Myocarditis from scorpion sting. BMJ 1:37476. http://dx.doi.org/10.1136/bmj.1.5327.374

[35] Romero N. O. -(2005) Cerebral edema associated to scorpion sting: a two-case sting report- J. Venom Anim Toxins Incl Trop Dis 11:4; pp 595-600 http://dx.doi.org/10.1590/S1678-91992005000400015.

[36] S. Mahadevan - (2000) Scorpion Sting - Personal Practice - Indian Pediatrics 37: pp 504-514

[37] Sandeep V. Binorkar et.al.,(2013) Effect of Ghrita Saindhava Dhara in the Management of Pain in Scorpion Sting - An Emergency Approach, Aryavaidyan-Quarterly Journal of Arya Vaidya Sala, Kottakkal, XXVI (3):181-184

[38] Shivprasad Sharma, (2006) Ashtang Samgraha, Indu Tika, Uttaratantra, Chapter 43, 1st Edn, Chaukhambha Publication, Varanasi

[39] Shyam Mathur, Sandeep Jain \& others - (2010) Scorpion Sting Presenting as Subarachnoid Hemorrhage in an Elderly Male- case report - Journal of The Indian Academy of Geriatrics, Vol. 6, No. 2 pp 171-172
[40] Suman sarkar- (2008) cerebrovascular manifestation and alterations of coagulation profile in Scorpion sting. Indian J.Crit. Care med. vol 12; 8. Pp-15-17 http://dx.doi.org/10.4103/0972-5229.40944.

[41] V. M. Kuttikrishna Menon, (1986) Kriya Kaumudi, Sahitya Praarthaka Co-Operatie Society Ltd., Trivendrum, Kerala

[42] Vera L. Petricevich - (2010), Scorpion Venom and the Inflammatory Response - Mediators of Inflammation - Volume 2010; pp 1-16. 